\title{
O curso de Secretariado Executivo como agente de formação de empreendedores
}

Recebido em 14.08.2015. Aprovado em 20.11.2016 Avaliado pelo sistema double blind review

\author{
Antonio Tavares costa \\ ratcosta@gmail.com \\ Universidade Federal do Amapá - Macapá - AP \\ Jessica Sabrina da silva \\ jessicacosta_unifap@hotmail.com \\ Universidade Federal do Amapá - Macapá - AP \\ Inajara Amanda Fonseca \\ inamanda@hotmail.com \\ Universidade Federal do Amapá - Macapá - AP
}

\begin{abstract}
Resumo
O empreendedorismo por ser uma nova realidade na profissão de secretariado, campo este que agrega inovações e criatividades e passou a ser uma área de importância para formação de empreendedores através do curso de Secretariado Executivo. Em busca de novas oportunidades de mercado e negócios os profissionais de secretariado executivo vêm ressaltando seus perfis como empreendedores uma vez que é bem preparado e qualificado academicamente através de sua formação, no entanto, deixa de atuar como assessor para empreender seus negócios, muitas vezes em outras áreas por desconhecer as possibilidades empreendedoras que a profissão lhes oferece. 0 estudo objetiva analisar se o curso de secretariado executivo está formando profissionais para 0 mercado de trabalho, atuação ou formação empreendedora incentivando 0 empreendedorismo como uma nova vertente profissional. A pesar de ser uma área voltada para assessoria executiva os profissionais necessitam descobrir novas atividades liberais desmistificando o fato de que só podem atuar com assessoramento executivo, pois como empreendedor de negócios na área secretarial terá sua auto-empregabilidade não apenas por necessidade, más por oportunidade contribuindo para a ascensão da profissão. A metodologia utilizada foi a pesquisa bibliográfica e entrevista com egressos do curso de secretariado executivo da Universidade Federal do Amapá - Unifap, sendo esta uma pesquisa exploratória e descritiva. Com este estudo, constatou-se que os profissionais possuem perfil empreendedor e que buscam por maiores satisfações pessoais e profissionais, confirmando-se ainda que há profissionais que se tornaram empreendedores de sucesso e que muitos pretendem ser donos de algum negócio, inclusive na área de secretariado.
\end{abstract}

Palavras-chaves: Secretariado. Empreendedorismo. Negócios

\begin{abstract}
Entrepreneurship to be a new reality in the profession secretarial, this field that combines innovation and creativity has become an area of importance for training entrepreneurs through the Executive Secretariat course. In search of new market opportunities and business the Executive Secretariat professionals are emphasizing their profiles as entrepreneurs since it is well prepared and qualified academically through his training, however, ceases to act as a consultant to undertake their business, often in other areas by ignoring the entrepreneurial opportunities that the profession offers. This study analyzes the executive secretarial course is to train professionals for the labor market, performance or entrepreneurial training by encouraging entrepreneurship as a new professional side. Despite being an area dedicated to business advice professionals need to discover new liberal activities demystifying the fact that they can only act with executive advice, because as a business
\end{abstract}


entrepreneur in the secretarial area will have their self-employment not only out of necessity, bad for opportunity contributing to the rise of the profession. The methodology used in this bibliographic research and interviews with graduates of executive secretarial course at the Federal University of Amapá - Unifap, which is an exploratory and descriptive research. With this study, it was found that professionals have entrepreneurial and seek further personal and professional satisfactions, confirming also that there are professionals who have become successful entrepreneurs and many want to own a business, including in the area of secretariat..

Keywords: Secretariat. Entrepreneurship. Business

\section{Introdução}

No que se refere ao tema "o curso de secretariado executivo como agente de formação de empreendedores", sua escolha se deu em prol deste fazer parte de uma gama de discussões acerca da área de empreendedorismo como atividade liberal para o profissional de secretariado, uma vez que este profissional tem buscado a expansão de suas atuações e a auto-empregabilidade, ao qual remete a um novo perfil profissional que pode ser identificado como "secretário empreendedor".

Hoje um tema muito discutido é o empreendedorismo: a formação de habilidades e competências gerenciais e empreendedoras, mais como os profissionais de secretariado executivo vêem a sua capacidade e a oportunidade de atuar como empreendedores de negócios exercendo a profissão aplicando seus conhecimentos profissionais deixando de ser assessor para atuar como empresário, tornando-se dono de negócios. Frente a isto, buscou-se averiguar como o curso desenvolve ações para o despertar destas pessoas para que possam desenvolver requisitos e características que os levem a empreender e se os egressos do curso de secretariado executivo estão criando empreendimentos e negócios na área após a formação.

Com base nestas informações, a questão que está a merecer urgente atenção é: Será que o curso de secretariado executivo está atuando devidamente como agente formador de profissionais para o mercado de trabalho, sua empregabilidade, atuação ou formação empreendedora? A partir do exposto, indaga-se: Como 0 profissional de secretariado pode ser visto no âmbito da capacidade empreendedora? 0 curso de Secretariado Executivo é agente formador de empreendedores?

Contudo, alguns profissionais encontram uma série de dificuldades, pois muitos acreditam que o melhor é estabilizar-se no setor público, na maioria das vezes, deixando de atuarem como secretários executivos não alcançando uma amplitude, tal qual a sua de dono do negócio enfrentando os desafios do mercado. Diante disso, levanta-se o seguinte questionamento: Quais as possibilidades de atuações do profissional de secretariado como empreendedor de negócios? Com suas competências, habilidades e experiências ao lado de executivos têm capacidade para ser um empreendedor de sucesso aplicando seus conhecimentos secretariais?

Nesse contexto, diante das dificuldades enfrentadas por estes no mercado e os paradigmas da profissão, em virtude de um cenário mercadológico desfavorável em alguns fatores, desde o contexto histórico da profissão os profissionais vem buscando adaptar-se as transformações organizacionais no mercado de trabalho e vem buscando novas alternativas e possibilidades de atuações dentro e fora das organizações.

Posto isso, a área secretarial está conhecendo um novo profissional, o secretário executivo inovador assumindo uma posição de responsabilidade no âmbito de empresário tornando-se dono de negocios e de empreendimentos, tomando decisões, exercendo a liderança e visualizando o campo empreendedorismo como uma área de oportunidades e não apenas necessidade, planejando ações a serem realizadas, controlando, organizando, dirigindo e executando atividades secretariais em seus próprios empreendimentos sem deixar de lado a área secretarial.

O objetivo deste trabalho centraliza-se em analisar se o curso de secretariado executivo está formando profissionais para o mercado de trabalho, sua empregabilidade, atuação ou formação empreendedora. A hipótese que norteou a elaboração da pesquisa é a de que os Bacharéis em Secretariado Executivo estão 
tornando-se empreendedores de negócios e passando a atuar como executivos face ao desenvolvimento de seu perfil contemporâneo e sua percepção de tornar-se dono de negócios não apenas por necessidade, entretanto, pelas oportunidades desmitificando a idéia de somente atuar como assessor por toda a carreira.

Atualmente, observa-se que para muitos profissionais de secretariado o problema é a falta de investimentos financeiros para a abertura de novos negócios, ou seja, fomentos. Além disto, há diversos fatores de desvalorização dos profissionais de Secretariado Executivo que influenciam na permanência ou ausência destes no mercado de trabalho como: gestores e executivos que desconhecem as atribuições dos profissionais, suas competências e habilidades que possuem tal qual para assumir um cargo de gestão ou tornar-se um executivo.

Deste modo percebe-se então que estes profissionais vêm buscando novas possibilidades de atuações como, por exemplo, a de ser um empreendedor de negócios, seja na área secretarial ou em outras áreas de acordo com a melhor opção no mercado. Adiante a este fato é indispensável que o curso de secretariado executivo norteie esta nova possibilidade aos acadêmicos para que possam aprender a trilhar novos caminhos e tenham a alternativa de optar por tornarem-se empreendedores de negócios já que a formação é ampla em variadas disciplinas e conhecimentos ofertados aos profissionais da área. Para fazer consistência a investigação da proposta abordada, problemática, hipóteses e resultados da análise foi realizada uma pesquisa de campo com aplicação de questionários com perguntas pertinentes para obtenção de êxito nas averiguações e propostas desta pesquisa que demonstrou a confirmação da hipótese.

Metodologicamente, o texto está organizado em quatro seções: A primeira vem ser a Introdução, a segunda aborda o "Empreendedorismo". Na terceira "Secretariado Executivo e Novas Frentes de Negócios". A quarta seção corresponde à metodologia e resultados da pesquisa de campo com realização de análise de dados seguido pela conclusão da pesquisa. Nas considerações finais deste trabalho serão apresentadas as conclusões de cada temática especialmente no que se refere a análise de dados. Diante deste prisma 0 propósito deste trabalho é, portanto, contribuir para as discussões acerca do tema empreendedorismo, relacionando-o, ao campo de atuação do profissional de secretariado executivo.

\section{Revisão Teórica}

O empreendedorismo possui seu papel fundamental para o desenvolvimento da sociedade e de um estado. Nesse sentido, é uma área que merece ser tratada com diferencial já que através da área serão geradas autoempregabilidade, satisfação profissional e desenvolvimento de competências e habilidades para profissionais das mais diversas áreas no mundo contemporâneo. Pela sua importância atualmente representa mais para 0 século XXI que revoluções representaram no século passado. Este por sua representatividade passou a ser uma nova vertente aos profissionais de Secretariado Executivo, tornando-se um novo prisma para abrilhantar e engrandecer os conhecimentos e a vida profissional de Secretários Executivos. Contudo, profissionais de Secretariado Executivo vem a partir deste, aperfeiçoando seus perfis empreendedores através da prática de seus conhecimentos com novos negócios buscando expandir sua área de atuação desmistificando o fato de somente atuar como assessor tendo em vista que é qualificado e preparado academicamente para obter capacidade de criar e inovar em várias frentes de negócios na área secretarial.

\section{Empreendedorismo}

Segundo ROBSON TAVARES A, C. (2008) em termo histórico, a palavra empreendedorismo deriva do Frances entrepreneur que traduzido no idioma Inglês da-se origem ao termo intrepreneurship, termo que se interliga a pessoas de negocios, inventores de novas criações. O empreendedorismo com a consolidação da sociedade capitalista passou a ter mais visibilidade e reconhecimento na sociedade tornando-se uma área em foco para pesquisas.

O empreendedorismo ainda é uma ciência moderna desde sua origem, uma novidade que com as mudanças históricas ganhou novos conceitos e definições de ângulos diferentes, entretanto, que falam de um mesmo 
tema. Uma forma de liberdade para criar e ousadia para inventar que só depende da criatividade das pessoas. Contudo, uma definição atual que aponta a realidade de uma temática contemporânea é a de DORNELAS (2001, p.37) que se baseia nas diversas definições já vistas, "o empreendedor é aquele que detecta uma oportunidade e cria um negócio para capitalizar sobre ela, assumindo riscos calculados" características de uma ação de empreender criando algo novo e diferenciado em meio às oportunidades com dedicação e persistência naquilo que se propõe a fazer para alcançar suas metas e objetivos assumindo riscos calculados.

$\mathrm{Na}$ busca por novos espaços e oportunidades os profissionais de secretariado aderiram ao empreendedorismo de negócios assumindo riscos em vista de oportunidades. O mercado passou a exigir ao longo das décadas profissionais com perfil empreendedor e intra-empreendedor tornando estes profissionais multifuncionais $\mathrm{e}$ cada vez mais polivalentes conforme NATALENSE (1995).

A partir disto os paradigmas relacionados à profissão começam a ser quebrados. Conceitos antigos, creditados erroneamente por indivíduos sem visão abrangente do contexto do mundo dos negócios, são revistos e substituídos. O secretariado executivo passa a ser fundamental nas organizações, junto aos executivos, na busca pelo lucro e no mercado competitivo inclusive aprendendo novas habilidades gerencias e competências para o empreendedorismo.

Nesse novo contexto, que continua com notórias evoluções até os dias atuais, GARCIA E D'ELIA (2005) sintetizam a evolução do perfil do profissional, focando-se no início da década de 1970 até os dias atuais: Enfim, o perfil do secretário do terceiro milênio deve reportar-se a um profissional com postura ética, empreendedora e negociadora. Ele é capaz de trabalhar em equipe e ser um agente de mudanças (AZEVEDO; COSTA, 2006). É alguém que desempenha papéis polivalentes, lidera grupos e mantém uma boa comunicação, bem como administra conflitos e relacionamentos entre clientes internos e externos.

Dessa forma, compete ao profissional secretarial a iniciativa de se adaptar ao novo perfil e aos futuros, pois diante de inúmeras mudanças dentro das organizações e no mercado de trabalho em um curto período de tempo, esse novo perfil secretarial se tornará obsoleto (AZEVEDO; COSTA, 2006). Tendo em vista que é necessário um diferencial para o futuro, a formação empreendedora que por sua vez vem ser uma otimização de preparo para secretários executivos. O profissional de secretariado pode ser um empreendedor empresarial, buscando um novo caminho para sua vida profissional na prática de seus conhecimentos acadêmicos adquiridos na universidade.

O empreendedorismo é uma nova competência para o novo perfil profissional de secretariado executivo que esta no mercado. As características empreendedoras aparecem no cotidiano destes profissionais. Os cursos de secretariado executivo exercem grandes influencias nas decisões dos mesmos em função da abrangência das disciplinas e dos conteúdos ministrados pelas universidades.

As instituições de ensino precisam preparar os acadêmicos para o mundo dos negócios. O sucesso é decorrente de diversos fatores e entre eles o perfil profissional destaca-se como ponto chave para obtenção do sucesso de qualquer profissional, dentre eles destaca-se o profissional de Secretariado Executivo. Segundo BARROS (2014, p.2,) "para que o sucesso aconteça, é necessária uma dose de visão de futuro, autonomia, organização, capacidade de estabelecer metas, autoconfiança, planejamento de carreira, network entre outras." $O$ profissional tem um perfil que se adéqua ao empreendedor por suas características singulares o que pode ser aperfeiçoado cada vez mais através de aprendizados e práticas empreendedoras e aprendizados contínuos.

Ser Secretária Empreendedora é ter prazer no trabalho mudando e transformando com toda energia e vontade tudo e todo trabalho ao seu redor, planejando e realizando com independência e auto-confiança suas atividades, correndo e assumindo os riscos, resistindo aos obstáculos e construindo pontes favoráveis, alinhando os objetivos com a missão maior da empresa. Os profissionais de Secretariado têm ma característica importantíssima; a intuição, capacidade esta que leva a melhor dimensionar os fatos, concretizar metas, aceitar os erros, recomeçar se necessário, aprender e reaprender, criar, solucionar problemas, confiar, flexibilizar e interagir. São profissionais que possuem o perfil que mercado busca e almeja.

Diante do contexto é imprescindível que os profissionais de Secretariado Executivo percebam novas frentes de negócios já que são profissionais estudam nas universidades empreendedorismo e gestão de negócios, 
atribuindo-lhes capacidade de gestão e empreendedor. Nesse contexto, suas experiências e sua qualificação Ihe permitem tornarem-se donos de negócios na área secretarial, porém observa-se que há diversos profissionais que empreendem em outras áreas tendo em vista que é importante propiciar aos mesmos que é possível empreender negócios na área a pesar de ser uma área voltada para o assessoramento executivo.

\section{Novas frentes de negócios}

Os tipos de negócios para os profissionais de secretariado executivo na área podem ser criativos e iniciados através de dois pontos chaves: pessoas e espaços. Assim, primeiramente, usar a criatividade e perceber o que se têm para criar, pois trabalhar com pessoas pode-se obter colaboração, interação, uma agenda de relacionamentos e ideias, através de espaço é possível obter criatividade, ferramentas, possibilidades, suportes, facilidades e coletividades.

Diante destes pontos chaves é importante enfatizar que a gama de conhecimentos dos profissionais da área permite que este profissional possa vir a trabalhar liberalmente como consultor em diversos tipos de atividades lidando com pessoas e organizações. Através de seu espaço empresarial organizaria, coordenaria e planejaria eventos e cerimoniais além de uma possível atuação como palestrante, prestando ainda serviços de diversas atividades secretariais, podendo também elaborar projetos e realizaria suas atividades enquanto profissional da área.

Uma nova opção de mercado para o profissional de secretariado seria um espaço virtual para mostrar serviços e prestação de serviços, assessoramento. Negócios com escritórios virtuais e consultorias. Com escritórios virtuais é possível uma troca de conhecimentos, prestações de diversos serviços com fornecimento de suporte para alcance de objetivos fins além de ser uma ótima forma de se aliar tecnologia e internet favorecendo as habilidades dos profissionais de secretariado com novas tecnologias. Dessa forma criaria então escritórios virtuais. Segundo DANUSA DIAS e CAMILA CUNHA (2014, p.35):

O profissional de secretariado precisa ter consciência de que sua atuação no mercado vai muito além da área da assessoria, ele é multifuncional e atua em uma área que possui muitas frentes de trabalho. Assim unindo seus conhecimentos obtidos na academia, acrescidos de experiência prática, e seu perfil empreendedor perspicaz entende-se que este pode sim ser o líder, e trabalhar por conta própria, pois este possui base, conhecimento, experiência prática, habilidades técnicas e outras tantas características que o permitem ter papel de gestor, com isso pode optar por trabalhar em outras áreas, como a consultoria, por exemplo, uma vez que este profissional possui amplos conhecimentos específicos na área de gestão, assessoria, consultoria e empreendedorismo.

O mercado de trabalho vem caracterizando-se por sua instabilidade e competitividade, dessa forma se torna cada vez mais importante que os profissionais busquem novas alternativas que possibilitem aumentar sua empregabilidade. Os profissionais de secretariado executivo hoje deixaram para trás aquele perfil caricato de servir café para exercer um perfil empreendedor com papel fundamental no mercado.

Uma das possibilidades de atuar como profissional autônomo é tornar-se um consultor, tendo em vista que pode consultorar em diversas áreas relacionadas há área de secretariado. Diante do contexto é importante se ter uma noção conceitual de consultoria. De uma forma abrangente consultoria vem ser uma prestação de serviço, ou fornecimento de determinada atividade por profissionais qualificados, especializados, experientes e conhecedores do tema ou serviço.

PORTELA (2009, p. 29), afirma da seguinte forma: "Os consultores, igualmente ao profissional de Secretariado Executivo, possuem todas essas características que os tornam capacitados a exercerem a consultoria".

Para o profissional de secretariado executivo é importante frisar que com a riqueza de conhecimentos adquiridos na graduação e a portabilidade para se especializar em diversas áreas é possível realizar consultoria em diversos segmentos como Consultoria em assessoria executiva atendendo executivos na realização de encontros de negócios e eventos, como seminários e palestras. Recepcionar clientes brasileiros e estrangeiros 
em visitas, congressos e convenções. Assessorando executivos em viagens nacionais e internacionais prestando serviços secretariais.

Consultoria em tradução e versão de idiomas, escrever textos em idiomas estrangeiros e traduzir documentos para o português. Fazer a tradução simultânea em reuniões, debates e seminários. Consultoria em organização de eventos locais, regionais, nacionais, internacionais, individuais ou coletivos realizando planejamentos e organizações de atividades como: roteiros de solenidades, orçamentos, provendo oradores, organizando decoração, mesas, tendas, prestando suporte e apoio ao evento e outros. Dessa forma buscaria novos formatos e experimentos na área de eventos.

Consultoria em gestão empresarial, trazendo através de um diagnóstico financeiro, avaliação dos processos operacionais e de gestão, permitindo identificar os pontos críticos e indicando as ações de melhorias necessárias, com conseqüências diretas nos resultados financeiros, qualquer que seja o porte e o ramo de atuação da empresa. Ajudando a empresa a melhorar a sua operação e gestão para obter os melhores resultados. Para DANUSA DIAS e CAMILA CUNHA (2014, p.32) "Uma boa consultoria leva em consideração as reais condições da empresa e do mercado e da conjuntura geral para atuar de forma a atingir os resultados esperados."

Um consultor de negócios influencia nas decisões de seus clientes, pois este aconselha, traz soluções, idéias e soluções além de estratégias. Ainda de acordo com as autoras esta atividade é possível aos profissionais de secretariado em vista destes terem visão generalista, com técnicas intelectuais, racionais, sociais e políticas de liderança. Como consultor recomenda, adverte, orienta e direciona as pessoas a enxergar o problema de uma forma mais clara e realista. Isto também se deve as experiências ao lado de executivos de alto escalão em empresas de grande porte, pois é um profissional que sabe lidar com situações novas e mercado.

Outra opção para estes seria a consultoria de negócios realizando encontro de negócios aproximando empresas que prestem serviços na área de secretariado executivo com organizações que precisam de profissionais qualificados na área, bem como em outros ramos além de proporcionar orientações sobre serviços, atividades na área secretarial e administrativa. Configurando-se em aconselhamento a executivos referente a todos os temas de negócios e pessoas aproximando as organizações e pessoas há área secretarial fazendo com que estes conheçam as atribuições e qualidades de um profissional de secretariado executivo.

Além destas, é preciso mencionar "coaching" treinamento em secretariado para desenvolver pessoas e talentos nas organizações ou através de seu próprio negócio apoiando, encorajando, motivando e acompanhando ações que melhorem o profissionalismo e a vida pessoal atingindo transformações positivas de acordo com o desejo dos clientes.

O profissional de secretariado executivo é um profissional preparado para propor soluções e respostas aos problemas, dificuldades e desafios, oferecendo também bons processos e novas criatividades como propostas para gestões e organizações que enfrentam no cotidiano as mudanças mercadológicas, gerando resultados, assim é importante destacar a capacidade deste de elaborar projetos, bem como mais uma oportunidade de atuar liberalmente.

Com consultoria é possível atuar como autônomo e na área de secretariado, pois desta forma os profissionais não precisariam deixar a área e a profissão fora de contexto profissional criando negócios em outros ramos. Pois mesmo que seja necessário analisar mercado e demandas para abertura de negócios, também é possível a criação de negócios na área, oportunizando até mesmo outros profissionais da área a atuarem profissionalmente em empresas de secretariado e consultoria prestando serviços.

Além de escritórios virtuais profissionais de secretariado poderiam ter escritório com vários profissionais associados para prestações de serviços a terceiros, ou trabalharem com terceirização de serviços administrativos e assessoria. Nesse contexto, os profissionais teriam mais tempo e qualidade de vida, com boas remunerações, em resumo a atuação liberal traz estes benefícios, gerando ainda satisfação e motivação profissional, pois profissionais qualificados querem estar no mercado de trabalho. Se o no mercado houverem fatores que influenciem na sua permanência ou ausência como empregado, estes podem criar e experimentar novas oportunidades de negócios na área. 
De acordo com DURANTE E BARBOSA (2013, p.17) através de um estudo observaram que o empreendedorismo é uma nova realidade para os profissionais de secretariado executivo onde segundo as autoras.

As características empreendedoras e intra-empreendedoras são potencializadas pela formação do Secretário Executivo que, por ser ampla e agregar conhecimento de várias áreas, dá embasamento e motivação para o profissional firmar-se como empresário de sucesso. Dessa forma, o exposto permite elucidar que o empreendedorismo é uma realidade na profissão secretarial.

Haja vista que tais novas opções de trabalho e atuação profissional sejam novos prismas de evolução na profissão secretarial, vale a pena apontar o empreender, o inovar, o criar um empreendimento, ou abordar a prática de inovar no mercado de trabalho através do empreendedorismo, não deixando de ser um profissional da área secretarial para tornar-se apenas um gestor de negócios, más ser um profissional de secretariado criando novas possibilidades de carreiras com capacidades além da gestão tornando-se gestor e empreendedor.

De acordo com DORNELAS (2001, p.10):

Todo empreendedor necessariamente deve ser um bom administrador para obter o sucesso, no entanto, nem todo bom administrador é um empreendedor. 0 empreendedor tem algo mais, algumas características e atitudes que o diferenciam do administrador tradicional.

$O$ autor destaca que nem todo empreendedor pode ser um bom gestor que venha obter sucesso. Diante do contexto, é importante frisar que os profissionais da área secretarial além da capacidade de gestão podem ser excelentes administradores de negócios e empreendedores dependendo da formação acadêmica e da sua vontade própria de buscar qualificar-se e de aprimorar seus conhecimentos para empreender.

A grandeza dos conhecimentos e a capacidade de criatividade dos profissionais de secretariado executivo são muito mais que apenas uma simples capacidade de gerir um negócio, secretariar ou assessorar. $\mathrm{O}$ que se tem observado no momento é que falta-lhes percepção de campos de atuações para novas possibilidades empreendedoras na área de secretariado executivo o que faz com que estes tornem-se empreendedores, porém em outras áreas, tornando-se assim empreendedor de negócios, más não na área de secretariado.

Resumidamente, compreende-se que falta um despertar de acadêmicos e egressos para possibilidades de atuações e negócios para o profissional de secretariado. Quanto mais oportunidades de negócios na área, maiores as chances da ascensão da profissão e vantagens de novas frentes de negócios para os profissionais de secretariado executivo.

\section{Procedimentos Metodológicos}

Quanto ao tipo de pesquisa e sua natureza esta se refere a um estudo exploratório e descritivo. A pesquisa exploratória ocorre de maneira que se permita o amplo e detalhado conhecimento do objeto estudado com finalidade descritiva para construção de hipóteses. Sendo a presente pesquisa descritiva os dados tendem a ser analisados individualmente.

Segundo GIL (2008) com uma pesquisa exploratória é possível familiarizar-se mais com o assunto estudado, para o autor quase sempre este tipo de pesquisa assume a forma de um estudo de caso. No que se refere aos objetivos está é uma pesquisa exploratória, sendo que como o próprio nome indica, a pesquisa exploratória permite uma maior familiaridade entre o pesquisador e o tema pesquisado, visto que este ainda é pouco conhecido, pouco explorado. Porém, de acordo com GIL (1996, p.78):

Por ser uma pesquisa bastante específica, pode-se afirmar que ela assume a forma de um estudo de caso, sempre em consonância com outras fontes que darão base ao assunto abordado, como é o caso da pesquisa bibliográfica e das entrevistas com pessoas que tiveram experiências práticas com o problema pesquisado. 
No que condizem aos procedimentos, esta se conduziu em uma pesquisa bibliográfica, ou seja, pesquisa exploratória, uma vez que em primeiro momento houve um estudo realizado a partir de material já publicado, constituído principalmente de livros, artigos de periódicos e atualmente com material disponibilizado na Internet no que condiz inicialmente com referencial teórico para estudo.

Em vista do apresentado, no que se refere a esta ser descritiva, tratou-se da descrição e caracterização dos dados dos entrevistados, com forma de aplicação de questionários. De acordo com OTANI e FIALHO (2011, p.36) explicam que este tipo de pesquisa "envolve a utilização de técnicas padronizadas, coleta de dados, questionário e observação sistemática. Em geral assume a forma de levantamento", em vista dessa referencia compreende-se que este tipo de pesquisa aprofunda o conhecimento da realidade além das aparências do que é apresentado explicando o porquê das coisas e ocorrência de fenômenos. Em relação ao critério de escolha e caracterização do banco de dados esta pesquisa é qualitativa e quantitativa.

Assim, como forma de comprovar as hipóteses levantadas foi realizada uma pesquisa de campo consistindo em investigações empíricas, com análises de fatos, na qual é uma forma de quantificar o tema abordado. Para atingir o objetivo proposto com base no referido assunto realizou-se uma pesquisa de campo subsidiada por questionários, com a função primordial de constatar os dados coletados na pesquisa bibliográfica, e ainda com o objetivo central de entender melhor o conceito sobre o curso de secretário executivo como agente formador de empregabilidade e empreendedorismo. Deste modo aliando a pesquisa bibliográfica com pesquisa de campo gerando teoria e prática.

Dessa forma, foram analisados os dados coletados conforme as principais temáticas abordadas no trabalho. 0 critério utilizado para a coleta de dados ocorreu da seguinte forma: primeiramente definiu-se o público alvo: egressos do curso de secretariado executivo. Solicitou-se junto à coordenação do curso de Secretariado Executivo da Universidade Federal do Amapá - Unifap uma relação cadastral de alunos concluintes do curso, entre os anos de 2000 a 2014. Os questionários foram aplicados para uma população com número de 168 pessoas, o que correspondeu a uma amostra com um total de 87 questionários respondidos pelos entrevistados, sendo que, 140 entrevistas foram realizadas através de e-mails, 18 questionários foram preenchidos através de contato pessoal, e apenas 10, foram obtidos por contato telefônico. Considerando que o levantamento foi realizado no período entre 28 de novembro a 20 de dezembro de 2014.

Quanto ao gênero sexual observou-se que o sexo feminino é predominante na profissão de secretariado executivo, 60 dos entrevistados foram mulheres e 27 homens apenas, completando as 87 entrevistas respondidas com êxito. Com intuito de realizar entrevistas pessoais com egressos, foi elaborado no programa Word, o modelo de questionário fechado contendo 13 perguntas com espaços para comentários opcionais correlacionados ao tema para fins de investigações, comprovações ou refutações de hipóteses. Foi elaborado no sistema Google Drive o mesmo modelo de questionário para enviar via e-mail aos entrevistados.

Todos os dados obtidos na coleta de dados foram incluídos no sistema on-line, em um programa no Google Drive, onde neste foi criado o questionário que foi enviado há e-mails para coleta de dados que facilitou a visualização das respostas, oferecendo gráficos e totais de respostas obtidas com dados coletados que correspondeu a pesquisa de campo onde serão apresentados a seguir por meio de gráficos e tabelas tabulados no Excel para geração de percentual de dados.

A finalidade do estudo consistiu-se em descobrir se o curso de bacharelado em secretariado executivo da Universidade Federal do Amapá está realmente formando profissionais com competências e habilidades, e despertando os acadêmicos da área para o empreendedorismo como uma nova possibilidade de atuação no mercado de trabalho já que é um agente na formação acadêmica. Contudo, tratando-se em descrever se 0 curso de secretariado executivo está formando profissionais para o mercado de trabalho, sua empregabilidade, atuação ou formação empreendedora.

\section{Pesquisa de campo e resultados}

Os resultados da pesquisa buscaram evidenciar as hipóteses presentes no referencial teórico, para tanto os 
dados mostraram inicialmente que apenas $74 \%$ dos profissionais de secretariado executivo estão trabalhando onde uma parte em sua grande maioria estão no setor público, uma pequena parte no setor privado e outro pequeno percentual é empreendedor de negócios. Neste contexto, observou-se também que $26 \%$ dos entrevistados estão desempregados e sem trabalho autônomo.

\section{Situação de empregabilidade dos profissionais de secretariado executivo no Amapá e novas possibilidades de atuações}

Observou-se que do percentual de $74 \%$ dos que estão trabalhando um percentual de $16 \%$ de profissionais formados em secretariado executivo atuam como secretários empreendedores e gestores. Tornaram-se "donos de seus próprios negócios" decidindo uma nova vertente de atuação profissional como empreendedores na qual correspondem estes dados. Este percentual reforça a tendência dos profissionais buscarem a expansão de suas atuações, o que já vem ser uma realidade desde os primórdios do surgimento da profissão por ser uma carreira que vem enfrentando os desafios do mercado de trabalho.

Contudo, nenhum dos entrevistados declarou-se ser empreendedor de negócios na área de secretariado. $\mathrm{A}$ pesquisa deixou evidente que $16 \%$ dos entrevistados tornaram-se empreendedores em outras áreas criando seus negócios em outros ramos em vista do que o mercado Amapaense oferece como oportunidade.

Uma outra realidade evidenciada pela pesquisa realizada e o que os secretários executivos entrevistados relataram quanto ao mercado de trabalho local, no estado do Amapá, é que o estado ainda necessita de maiores desenvolvimentos para abrir novas possibilidades empregatícias e oportunidades de carreira, sendo que parte das empresas locais não possuem estrutura para absorver profissionais bem capacitados e preparados para ingressar no mercado de trabalho.

Profissionais apontaram o fato de o Estado não ter empresas de grande porte para agregar os profissionais de secretariado executivo, uma vez que o curso é voltado para o mercado de trabalho. Por este motivo os profissionais tendem a buscar novos caminhos profissionais, entre eles o empreendedorismo. Além destes fatos a pesquisa demonstrou que parte dos entrevistados exerceu a função de secretariado executivo, entretanto, no reconhecimento em carteira profissional poucos obtiveram registro na Carteira de Trabalho Profissional com título de secretário executivo. Neste contexto, muitos tiveram títulos como assistentes ou auxiliares administrativos apenas, em sua maioria.

Isto reforça a falta de reconhecimento por parte das organizações do estado em reconhecer as competências e habilidades que estes profissionais adquirem na academia além de não realizarem os devidos registros para não pagarem o piso salarial ao qual faz jus a categoria como demonstraram os dados em que $45 \%$ dos entrevistados afirmaram ter exercido atuação na área especificadamente apenas quando ainda estudavam e eram estagiários, enquanto apenas $55 \%$ já exerceram a função específica com reconhecimento.

Um outro fato relevante a abordar nesta análise é que parte dos profissionais que estão no setor público, não atuam na área de secretariado executivo, haja vista que ainda há poucos concursos públicos na área e quando há são poucas vagas para o cargo. Além deste fato uma observação a respeito deste fato é que muitos cargos de secretariado dentro do estado são ocupados por pessoas não qualificadas e sem a formação acadêmica, 0 que dificulta a ascensão da profissão dentro do Estado.

Ainda com a análise de dados objetivou-se investigar que concepção os profissionais de secretariado executivo tinham a respeito do empreendedorismo como uma nova alternativa de empregabilidade e atuação no mercado. Deste modo levantou-se o seguinte questionamento: Se ser empreendedor de negócios seria uma alternativa de empregabilidade para os secretários executivos? Onde foi extremamente relevante para saber se os profissionais tinham visão de que o empreender é uma portabilidade de manter-se empregado e atuar no mercado como mostra a analise a seguir. 


\section{O empreendedorismo de negócios como uma alternativa de empregabilidade para os profissionais de Secretariado Executivo.}

Foi satisfatório o resultado deste questionamento resultando em um percentual de $98 \%$ de entrevistados, onde se constatou que estes compreendem e sabem que o empreendedorismo faz parte do perfil de um profissional de secretariado executivo. Constatou-se ainda que muitos profissionais almejam tornar-se empreendedores de negócios enquanto não aparecem boas oportunidades no mercado Amapaense.

Em relação ao perfil de um profissional de secretariado executivo empreendedor, os entrevistados afirmaram que "o secretario executivo é um gestor e empreendedor nato, são profissionais versáteis e ágeis, o que é impressionante para o perfil empreendedor". De acordo com os entrevistados: o empreendedorismo faz parte das habilidades dos secretários executivos, pois o profissional enquanto acadêmico estuda para ter visão holística, ou seja, visão futurística e teoricamente é preparado academicamente para desenvolver habilidades empreendedoras ainda na universidade.

Segundo os profissionais entrevistados, os profissionais podem ser criativos, inovadores, cheio de ideias que podem ajudar no crescimento dos negócios, entretanto, apontaram para um despertar da universidade em criar uma disciplina que possibilitasse a prática do empreender dentro da universidade, como por exemplo um laboratório, além da empresa Junior, mais prática nesta, aliada a teoria. Para os entrevistados inovação é a palavra-chave, para eles o secretario executivo tem sempre novas visões do futuro.

A pesquisa evidência que mesmo que se considere que a maior parte dos secretários executivos entrevistados admitam que o empreendedorismo faça parte do perfil profissional de um secretario executivo e que considerem que o empreendedorismo seja uma ancora para a empregabilidade trazendo a possibilidade de atuar como gestor e empreendedor de negócios aplicando seus conhecimentos, ainda assim são poucos secretários que empreendem em algum negócio no estado correspondendo a um percentual de apenas $16 \%$ como mostra 0 gráfico a seguir.

\section{Profissionais de secretariado executivo que são empreendedores e gestores de seus próprios empreendimentos}

Observou-se que os negócios e empreendimentos não são na área secretarial, entretanto, os gestores são profissionais de secretariado executivo e que afirmam ter interesse em abrir novos negócios na área da profissão. Por outro lado enfatizam ter visão de mercado e perceber o melhor ramo para investir em negócios já que o importante é que são empreendedores e gestores de seus próprios empreendimentos conquistando salários ótimos além de poder ter reconhecimento como empreendedores de sucesso no estado já que há mercado para tal.

Diante do percentual de $84 \%$ de profissionais que nunca empreenderam em algum negócio ou não empreendem em nada pôde ficar evidente o fato de que ainda é necessário levar em conta que alguns profissionais ainda acham que ser secretario executivo é apenas ser assessor deixando de levar em consideração que o profissional da área tem diversas possibilidades de atuações entre elas a de empreender negócios, até mesmo na área secretarial. Entretanto, observou-se que $52 \%$ destes já estão pensando entrar para a estatística de secretários empreendedores no estado tornando-se dono de seus próprios empreendimentos como mostram os dados.

Este fato comprova a tese de que os profissionais de secretariado estão trilhando novos caminhos profissionais voltados ao empreendedorismo de negócios, comprovando a importância do despertar o empreender dentro do curso uma vez que é a chance de agregar esta nova realidade como alternativa de valorização da profissão frente a situação real que a universidade e o estado precisam encarar como solução a tantos embates e desmotivações que a categoria vem sofrendo.

Nesta mesma realidade ficou constatado que parte dos entrevistados pretendem tornar-se empreendedores de negócios, mudando sua visão a respeito de atuações profissionais pretendendo dar um salto na vida profissional ou sair do desemprego. De acordo com os argumentos dos egressos é que há mercado no estado, entretanto, 
não há valorização da classe, onde os mesmos estão pretendendo buscar a expansão de suas atuações abrindo caminhos para novas atuações e possibilidades empregatícias. Desta forma os mesmos buscam uma nova forma de alavancar e valorizar a profissão em questão onde como empregados não conseguem obter este êxito.

\section{Profissionais de secretariado executivo que pretendem ser empreendedores e gestores de seus próprios empreendimentos}

Com a análise é possível constatar que do percentual de $52 \%$ que pretendem empreender parte estão desempregados e parte já estão trabalhando na área privada e setor público. Do percentual de $48 \%$ que não tem nenhum interesse em empreender em nenhum negócio em sua grande maioria já tem uma estabilidade econômica pessoal, uma vez que são funcionários públicos. Partindo deste ponto é viável compreender a variável de que o empreendedorismo é uma alternativa de empregabilidade e de geração de renda.

Apesar deste imparcial resultado $100 \%$ dos entrevistados concordaram que o profissional de secretariado executivo pode sim ser gestor e empreendedor de negócios. O que importa para o empreender como um novo destaque e ascensão na profissão de secretariado executivo. No que remete a atuação desses profissionais nos dias de hoje verificou-se que estão buscando expandir suas áreas de atuações. Segundo os entrevistados:

Para os profissionais é preciso buscar novos caminhos em vista das dificuldades para nós enquanto profissionais da área aqui no estado do Amapá, a falta de conhecimento da sociedade sobre a profissão de secretariado estigmatiza o secretario a atender telefone e servir café

Os profissionais de secretariado compreendem que mesmo que no estado haja dificuldades e paradigmas a serem superados, nacionalmente a profissão é bem vista pela sociedade e no meio empresarial. Alguns entrevistados apontaram um fato interessantíssimo de que o profissional de secretariado executivo é mais para a atividade de gestão que a simples assistência executiva, por isso vem buscando atuar na área do empreendedorismo. Outro motivo que impulsiona os mesmos a buscarem a expandir suas áreas de atuações é a competitividade e as mudanças constantes no mercado de trabalho.

Diante dos fatores apresentados concluiu-se que muitos profissionais da área querem estabilidade financeira e profissional por isso buscam o empreendedorismo. De acordo com as entrevistas "os profissionais precisam ter mais estabilidade profissional e no empreendedorismo há oportunidade de se estabilizar financeiramente e profissionalmente". O Amapá tem demandas e oferece um mercado com oportunidades para empreender, pois os entrevistados confirmaram que os profissionais possuem as habilidades para isto e o curso os prepara para tal atividade.

Na pesquisa buscou-se averiguar se o curso bacharelado em secretariado executivo formou profissionais com competências e habilidades que garantam ou norteiem os concluintes a ingressar no mercado de trabalho e de que forma estas poderiam ser melhoradas para garantir empregabilidade aos profissionais.

\section{Desenvolvimento de competências e habilidades na graduação para geração de empregabilidade.}

Observou-se que o percentual de entrevistados que acreditam que precisa ter desenvolvimento de maiores competências e habilidades dentro do curso é um média $94 \%$ um total considerável para reflexão. Para os que disseram sim, para que essas habilidades e competências sejam melhores desenvolvidas é preciso que o curso venha se desenvolver e expandir-se dentro da própria universidade pela sua importância ajudando a profissão a crescer mais no estado.

Dentro deste contexto, de acordo com os dados da pesquisa as amostras revelam que teoria é fundamental e que a prática é essencial para o desenvolvimento dessas habilidades e competências, quanto mais capacitação dentro do curso melhor para que esse desenvolvimento. Atualmente o curso vem buscando isto, um exemplo evidente é a Empresa Júnior, que não deixa de ser uma prática laboratorial. Entretanto, dos $6 \%$ que estão satisfeitos com o resultado que obtiveram durante a graduação, em relação as competências e habilidades, em sua maioria acreditam que depende apenas de cada profissional para esse desenvolvimento da seguinte forma: 
com capacitação, cursos de aperfeiçoamento, participação em seminários, fóruns e outros. Dessa forma observou-se que estes não levaram em consideração o fundamental papel da universidade, ou desconhecem este fato, pois a formação e o papel de geração de empregabilidade da universidade não termina com a colação de grau. Já que a universidade é responsável por formar profissionais e preocupar-se com a situação destes no mercado.

Deste ponto é compreensível que Isto ajudaria no reconhecimento da profissão, ma divulgação do perfil dos profissionais de secretariado executivo no estado, já que o curso é voltado para a empregabilidade e possui um ótimo componente curricular por que não torná-lo mais completo instigando e integrando ao currículo do curso disciplinas especificas que levam ao caminho do empreendedorismo, pois é válido salientar que isto pode mudar o rumo profissional de um secretário executivo.

Uma alternativa abordada para o desenvolvimento das habilidades e competências durante a graduação é 0 treinamento especializado através de empresas de prestação de serviços de assessoria e empreendedorismo ou treinamento por meio de professores que ofertem disciplinas especificas de empreendedorismo com aulas práticas. Esta é uma sugestão de egressos. Para uma análise verificou-se a concepção e o ponto de vista dos egressos do curso de secretariado para verificar a opinião a respeito do curso, para saber se o curso realmente prepara os formandos para ingressar no mercado de trabalho e enfrentar seus desafios

\section{0 curso de secretariado executivo como agente formador e preparatório para ingresso no mercado de trabalho.}

0 resultado demonstra que $70 \%$, bem como a maioria dos entrevistados que o curso é uma excelente graduação, com ótimas disciplinas e currículo acadêmico. De acordo com as respostas os estágios nas organizações são a causa e principal razão de complemento para formar profissionais experientes e capacitados. Outra razão é o currículo do curso com sua diversidade de disciplinas teóricas e por ser bastante completo, isto explica o por que de preparar os formandos para ingressar no mercado de trabalho. Nas respostas os egressos explicaram que o curso de secretariado executivo é voltado para o mercado de trabalho, é um excelente curso de graduação, com ótimas disciplinas e currículo acadêmico.

$30 \%$ dos egressos afirmam que o curso precisa melhorar revendo algumas disciplinas que fazem parte da grade do curso, trazendo mais prática dentro da universidade aliando a teorias, necessitando ser mais exigente, dinâmico e específicos em determinadas disciplinas, enfatizando no idioma como um ponto chave para inclusão no mercado de trabalho. De acordo com a opinião destes o curso precisa desenvolver-se, ainda é necessário alguns avanços no curso, entre eles os poucos professores que fazem parte do curso, a falta de um laboratório específico para que disciplinas e assuntos acadêmicos não sejam vistos de forma acelerada impactando no desenvolvimento acadêmico.

Mesmo com todas as dificuldades e obstáculos que o curso vem ultrapassando dentro da universidade para desenvolver-se e trazer com esse desenvolvimento melhorias na graduação e no desenvolvimento de melhores habilidades e competências conclui-se nesta análise que o curso forma profissionais competentes e preparados para ingressar no mercado de trabalho enfrentando desafios, apenas o que os dados evidenciam diante disto é que o curso precisa abrir e mostrar novos caminhos empreendedoriais para não deixar que os profissionais formem-se sem norteio de oportunidades, formando profissionais com visão empreendedora.

Os entrevistados reconhecem que é preciso muito curso de aperfeiçoamento, entretanto o curso em si já deveria abrir caminhos para a empregabilidade dos egressos, compromisso da universidade com, qualidade no ensino, apoio, prática, teoria, pós-formação e incentivo. Estes são fatores que reforçam um passo a frente dos demais no mercado por ter obtido uma formação com diferencial.

Para fins de verificar o que a universidade tem feito para apoiar, incentivar, ou responsabilizar-se de alguma forma pelo ingresso de profissionais formados no mercado de trabalho buscou-se na pesquisa de campo perguntar aos entrevistados. 


\section{Formação Acadêmica e Responsabilidade da Universidade para com Ingresso de Profissionais de Secretariado Executivo no mercado de trabalho.}

Diante das informações coletadas com a pesquisa percebeu-se que os egressos não tiveram apoio da universidade, incentivos ou contato de alguma forma com a instituição. $84 \%$ dos egressos afirmaram que sempre tiveram que agir de forma independente, e buscar oportunidades sozinhos sem norteio ou colaboração da Unifap e do curso de secretariado executivo. Neste sentido, os acadêmicos informaram que sempre procuram buscar oportunidades empregatícias antes mesmo de formar por receio de sair da universidade e ficar desempregado. Não intermediação da instituição para ingresso no mercado pós formação ou intenção de projetar ações para ajudar a divulgar e desenvolver o profissional e o curso para o mercado local até mesmo abrindo caminhos para os mesmos.

É importante salientar a dificuldade até para encontrar os egressos, haja vista que na coordenação do curso não há um cadastro em banco de dados com fácil visualização, o que dificulta até o contato com os egressos e a instituição. $O$ que seria de fundamental importância para acompanhar os profissionais no mercado e reter informações essenciais para o desenvolvimento do curso.

Neste sentido, também é compreensível e importante frisar que o profissional formado não pode se isentar da responsabilidade em zelar pelo seu compromisso profissional, suas atualizações constantes e interesse para a excelência no exercício da profissão. Este é um fator que $92 \%$ dos entrevistados reconhecem, pois somente diploma de graduação e formação acadêmica não garantem empregabilidade. Os profissionais também precisam atender as expectativas do mercado para que este continue sendo um ponto favorável aos profissionais no mercado e para o desenvolvimento e crescimento do curso, na qual é a realidade atual.

Na possibilidade de averiguar o mercado e as possibilidades empregatícias para o profissional de secretariado executivo foi perguntado aos mesmo, que por sua vez profissionais bem capacitados no mercado se as expectativas de empregabilidade no estado do Amapá eram boas.

\section{As perspectivas de empregabilidade para o profissional de secretariado executivo no estado do Amapá.}

É perceptível que mais da metade dos entrevistados responderam que sim, dentro desta análise sendo uma das mais importantes deste trabalho é válido reforçar que o profissional de secretariado executivo é de grande importância para uma organização. Visto que sua mutifuncionalidade, sua visão e seus conhecimentos trazem benefícios as empresas, principalmente por serem versáteis e ágeis em relação às mudanças como um todo. Os dados confirmam que $47 \%$ dos profissionais que responderam sim confirmando que há mercado no estado já ingressaram no mercado de trabalho, entretanto, afirmam que ao mesmo tempo em que o estado oferece boas demandas de trabalho poucas empresas querem pagar bons salários a profissionais competentes e com formação superior mesmo que de qualidade.

Sobre o assunto Marcelo Castro (Bel. em Secretariado) argumenta: "O mercado não possui estrutura para agregar novos profissionais formados sendo que são poucas as demandas em empresas que pagam bons salários a pesar de ter mercado para os profissionais no estado do Amapá." Fica evidente que a sociedade Amapaense pouco conhece sobre a capacidade e a necessidade de se obter um profissional de secretariado em uma organização devido sua importância profissional e sua capacitação.

A pesquisa deixa evidentemente claro que o estado do Amapá possui muitas limitações para demandar vagas em secretariado executivo no setor público para concurso público, sendo que quando há concursos poucas vagas são pleiteadas, uma vez que mesmo o mercado oferecendo vagas pouco é o reconhecimento e a valorização do profissional no mercado.

Sobre esta questão Graciane Leão (Bel em Secretariado) Comenta:

A sociedade amapaense é leiga quanto às atribuições do Secretario Executivo. Há muitas 
pessoas atuando no lugar do profissional de Secretário Executivo no mercado, uma vez que essas vagas deveriam ser ocupadas por profissionais com a devida qualificação, inclusive no setor público.

Sobre este assunto é importante ressaltar que além deste fato parte das organizações que querem contratar profissionais de secretariado não querem contratar profissionais como secretários executivos, más sim como auxiliar administrativo, assistentes, recepcionistas entre outros assim desvalorizando ainda mais a categoria. Este fato pode ser comprovado pelo gráfico 1 onde os dados comprovam que a maioria dos profissionais que realmente exerceram a função específica como secretario executivo exerceram nos estágios intermediados pela universidade durante o curso. A pesquisa comprovou a dificuldade para os profissionais em descobrir empresas que reconhecem e sabem o que faz e o que é um profissional da área secretarial.

Muitos entrevistados levantaram questionamentos de que o mercado Amapaense não está preparado para receber um profissional com um perfil ao qual a universidade forma com grandes competências, Isto caracteriza a iniciativa dos profissionais estarem buscando novas oportunidades. A partir deste ponto é que surge a importância de frisar o incentivo ao empreendedorismo, fomentar atividades, incentivar a capacitação individual/empresarial gerando assim alternativas que desenvolvam não somente 0 curso, más o estado e a região.

Em virtude de o cenário ser desfavorável aos profissionais de Secretariado Executivo, cabe aos mesmos fazerem uso de seus conhecimentos para gerar oportunidade em sua carreira profissional, buscando uma remuneração compatível com a sua graduação. $O$ que se torna interessante para os profissionais fazer negócios por oportunidade e não apenas por necessidade. Com um percentual de $53 \%$ a maioria dos egressos afirmou que não há boas expectativas de empregabilidade no estado do Amapá para o profissional de secretariado executivo, há demandas e vagas no mercado mais o mercado não tem estrutura para comportar profissionais capacitados por falta de reconhecimento da profissão e dos profissionais em questão.

Um dos fatores que contribui para a insuficiência de mercado de trabalho para os profissionais em Secretariado Executivo decorre da ausência de investimentos da própria Instituição de Ensino que não oferece aos profissionais do curso alternativas de empregabilidade voltadas para o empreendedorismo como um diferencial aos profissionais que não encontrarão no mercado satisfação e oportunidades em grandes empresas que reconheçam esses profissionais.

Por ser a mantenedora do curso, a Universidade deveria ser a maior incentivadora do cargo, abrindo concursos públicos e, desta forma, incentivando outras instituições públicas e/ou privadas. Além disto, incentivar 0 empreendedorismo e outras alternativas para geração de empregabilidade para que um profissional de secretariado executivo possa enfim, ter alternativas, oportunidades e características diferenciáveis que possam trazer satisfação na profissão dentro do estado do Amapá.

\section{Considerações Finais}

A inserção do empreendedorismo na área de secretariado vem ser uma nova forma de potencializar a profissão e demonstrar aos profissionais da área que é possível a constituição de seus próprios negócios na área. 0 tema empreendedorismo neste sentido vem ser mais uma nova abordagem na área de Secretariado Executivo, o que é decorrente de mudanças tecnológicas e econômicas que influenciam o mercado atual. 0 empreendedorismo vem surgir como mais uma nova vertente de atuação para os profissionais de secretariado, uma vez que estes almejam empreender na área secretarial e por este ser uma tendência a ser reforçada pelos profissionais da área no país já que buscam sempre estar criando e acompanhando novas tendências no mercado.

O apoio da universidade e do curso é fundamental para que desta forma a categoria possa através do empreendedorismo conquistar a valorização profissional almejada diante da possibilidade de atuação no mercado de trabalho, com o empreendedorismo, uma vez que há oportunidades de fazer seu próprio salário, havendo um nível de maior satisfação remunerativa, profissional ou pessoal colocando em prática seus conhecimentos e sair do paradigma de ser para todo o sempre somente um assessor, ou deixar de exercer a profissão, migrando para outras áreas de atuações, até mesmo no setor público desfavorecendo novas 
mudanças na profissão.

Para DURANTE E BARBOSA (2013,p.2): "O Secretário Executivo vem ressaltando seu perfil empreendedor e intra-empreendedor e, em consequência, constituindo seu próprio negócio." Dessa forma esta nova vertente é compreendida como o empreendedorismo secretarial para profissionais de Secretariado Executivo. Nesse sentido o Profissional de Secretariado entre as variadas possibilidades de atuações, vem ser um profissional de muitas habilidades e competências que agregam seu perfil, onde seu papel vai além de apenas atividades operacionais, tal quanto possa vir a tornar-se empreendedor assumindo função executiva.

A pesar da falta de percepção dos egressos em empreender na área secretarial em vista da carência de novas frentes de negócios na área, ficou comprovado que o curso de Secretariado Executivo é agente de formação de empreendedores. Após a análise dos dados obtidos foi possível compreender que estes possuem uma abrangente formação acadêmica que lhes da competências e habilidades para tornarem-se empreendedores de negócios. Portanto, esta pesquisa demonstra que ser empreendedor não é deixar de ser ou exercer a profissão, más apenas uma nova oportunidade profissional.

\section{Referências}

AZEVEDO, Ivanize; COSTA, Sylvia Ignácio Da. Secretária - um guia prático. 4 ed. São Paulo: SENAC, 2006.

BARROS, Fernanda Angélica de; KAFROUNI, Maria Ângela Sant'Anna. O ensino do empreendedorismo como complementação para o desenvolvimento do perfil profissional do jovem e seu primeiro emprego, 2014.

COSTA, Robson Antonio Tavares Da. Formação de empreendedores por meio de treinamento empresarial: "um estudo de caso com base nos dados disponibilizados pelo EMPRETEC Amapá - 2008" publicado em 2011.

DURANTE, Daniela Giareta; BARBOSA, Sheila Mara Costa. Secretariado Executivo e Empreendedorismo: Realidade ou utopia?, 2013.

DORNELAS, José Carlos Assis. Empreendedorismo: transformando idéias em negocios - Rio de Janeiro: Elsevier, 2001.

GARCIA, Edméa e D'ELIA, Maria Elizabete Silva. Secretária Executiva. São Paulo: IOB Thomson, 2005.

GIL, Antonio Carlos. Como elaborar projetos de pesquisa. 5. ed. São Paulo: Atlas, 2008.

GIL, Antônio Carlos. Como Elaborar Projetos de Pesquisa. $3^{\circ}$ ed. São Paulo: Atlas, 1996.

NATALENSE, M. L. C. Secretária Executiva: manual prático. São Paulo: IOB, 1995.

OTANI, Nilo; FIALHO, Francisco Antonio Pereira. TCC - Métodos e Técnicas, $2^{a}$ edição revista Atualizada Florianópolis: Visual Books, 2011.

PORTELA, Keyla Christina Almeida; SCHUMACHER, Alexandre José. Ferramentas do Secretário Executivo. São Paulo: Viena, 2009.

PORTELA, K. C. A.; SCHUMACHER, A. J. Gestão secretarial: O desafio da visão holística. Cuiabá: Adeptus, 2009. v. I.

VILHENA, Camila Carolina Cunha; DIAS, Danusa de Oliveira. O Secretario Executivo Atuando Como Profissional Liberal: Novas Possibilidades No Mercado, 2014. 